\title{
FARINHA MISTA DE TRIGO E BERINJELA: CARACTERÍSTICAS FÍSICAS E QUÍMICAS
}

\author{
PATRÍCIA MARIA PÉRICO PEREZ * \\ ROGÉRIO GERMANI **
}

O objetivo deste trabalho foi estudar as características físicas e químicas da farinha de berinjela pura e em combinação com farinha de trigo. A farinha de berinjela apresentou elevado teor de fibra alimentar total e alta quantidade de proteína, de cinzas e de açúcares totais. Maior concentração de farinha de berinjela em misturas com a farinha de trigo aumentou significativamente os teores de proteína, de sais minerais e de fibra alimentar total das farinhas mistas. O alto teor de fibra alimentar da farinha de berinjela permite apontá-la como alternativa para uso em mistura com farinha de trigo na elaboração de produtos de panificação (biscoitos, pães e massas alimentícias). Maior quantidade de farinha de berinjela na farinha mista amplia a capacidade da mistura em absorver água, podendo aumentar o rendimento da massa em produtos de panificação. A farinha de berinjela é facilmente obtida na granulometria da farinha de trigo, facilitando sua homogeneização.

PALAVRAS-CHAVE: BERINJELA-CARACTERIZAÇÃO FÍSICA E QUÍMICA; FARINHA DE TRIGO; FARINHA MISTA; FARINHA DE BERINJELA.

\section{INTRODUÇÃO}

A berinjela pertence à família Solanaceae, gênero Solanum, da espécie Solanum melongena, L. (EMBRAPA HORTALIÇAS, 2001).

Parece certo que os árabes (na Espanha) e os padres carmelitas (na Itália) tenham contribuído para a difusão do consumo da berinjela.

* Nutricionista, Mestre em Ciência e Tecnologia de Alimentos, Departamento de Tecnologia de Alimentos, Universidade Federal Rural do Rio de Janeiro, Seropédica, RJ (e-mail: pmperico@uol.com.br).

** Engenheiro Químico, PhD em Ciência dos Cereais, Pesquisador da Embrapa Agroindústria de Alimentos, Rio de Janeiro, RJ (e-mail: germani@ctaa.embrapa.br). 
Aliás, esses últimos foram os primeiros a descobrir suas propriedades terapêuticas (GUIMARÃES et al., 2000).

A berinjela, amplamente consumida no Brasil e em outros países, tem sido empregada na medicina popular como agente hipocolesterolêmico em virtude do seu alto teor de fibra alimentar (JORGE et al., 1998).

Uma das maneiras de reduzir as perdas e diversificar o uso da berinjela seria a secagem e sua transformação em farinhas para incorporação em diversos produtos, em especial os de panificação.

Com o reconhecimento da importância da fibra alimentar para a saúde humana tem-se observado interesse crescente pela incorporação de fibras em produtos alimentícios (ARTZ et al., 1990).

Várias farinhas podem ser misturadas à farinha de trigo para uso em produtos de panificação, denominando-se tal mistura de farinha mista ou composta (EL-DASH e GERMANI, 1994).

Inúmeros estudos têm sido realizados no sentido de substituir o trigo na elaboração de produtos de panificação devido à restrições econômicas, exigências comerciais, novas tendências de consumo e hábitos alimentares específicos.

A percentagem de farinha de trigo necessária para garantir bons resultados em farinhas mistas depende da qualidade e da quantidade da proteína do trigo, bem como da natureza do produto envolvido (HOSENEY, 1990). É necessário, portanto, que os alimentos escolhidos para integrar farinhas mistas sejam pesquisados quanto à composição química e características físicas e nutricionais para desenvolvimento de tecnologia que permita seu uso em produtos de panificação de forma eficiente (SILVA, 1997).

Informações sobre a composição química e nutricional da berinjela na forma de farinha são escassas, apesar da ampla utilização da berinjela na culinária brasileira.

O objetivo deste trabalho foi estudar as características físicas e químicas da farinha de berinjela pura e em combinação com a farinha de trigo, bem como avaliar o potencial nutricional dessas farinhas. 


\section{MATERIAL E MÉTODOS}

A berinjela (Solanum melongena, L.) in natura, sem injúrias (defeitos biológicos, genéticos e/ou mecânicos), e apresentando excelente nível de sanidade foi adquirida em estabelecimento hortifrutigranjeiro na cidade do Rio de Janeiro (RJ). Os frutos apresentavam coloração roxapúrpura, quase preta, superfície lustrosa, polpa macia, comprimento médio de $15 \mathrm{~cm}$ e peso médio de $356,67 \mathrm{~g}$. Estavam fisiologicamente imaturos (ponto ideal de colheita), pois quando maduros podem ficar amargos.

Adquiriu-se a farinha de trigo no comércio da cidade do Rio de Janeiro (RJ).

\subsection{OBTENÇÃO DA FARINHA DE BERINJELA}

Berinjela pré-lavada em água corrente foi submetida à sanificação durante 10 minutos. Usou-se água clorada em temperatura ambiente ( $\left.\pm 24^{\circ} \mathrm{C}\right)$, contendo $150 \mathrm{ppm}$ de cloro residual livre e pH 6,0. Os "cálices" (parte superior verde que reveste o fruto) foram retirados e as berinjelas cortadas em fatias transversais de $2 \mathrm{~cm}$ de espessura, usando-se processador de legumes. As fatias foram acondicionadas em bandejas de aço inoxidável, providas de telas de fios de "nylon", as quais foram colocadas em secador de cabine, a 60으, com circulação de ar $(0,5$ a $1,0 \mathrm{~m} / \mathrm{s}$ ) por 24 horas. O referido secador, com capacidade para até $100 \mathrm{~kg}$, foi desenvolvido pela Embrapa Agroindústria de Alimentos. A cada $4 \mathrm{~h}$ efetuou-se rodízio de bandejas. Após alcançarem umidade final em torno de 5,0 a $10 \%$, as berinjelas foram primeiramente trituradas em moinho de facas e depois moídas em moinho de martelos com peneira de $1 \mathrm{~mm}$ de diâmetro (Figura 1).

A farinha de berinjela resultante foi acondicionada em embalagem metalizada, com revestimento de polietileno, impermeável a luz, umidade e odores, e armazenada a $-20^{\circ} \mathrm{C}$ até sua utilização.

\subsection{PREPARO DA FARINHA MISTA DE TRIGO E BERINJELA}

As farinhas de trigo e de berinjela foram misturadas nas proporções de 90:10; 85:15 e 80:20, sendo as farinhas resultantes designadas como fórmulas I, II e III, respectivamente. 


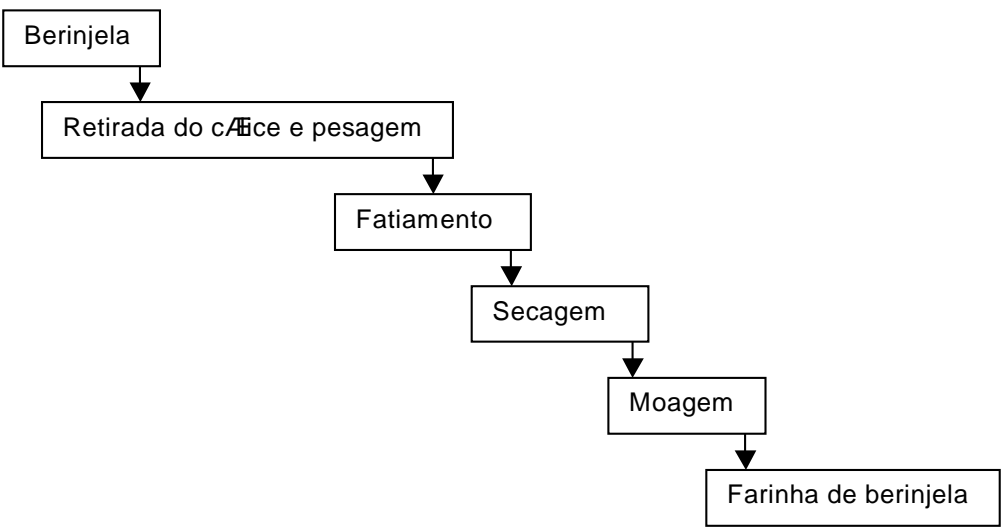

2.3 CARACTERIZAÇÃO QUÍMICA DA FARINHA DE TRIGO (FT), DA FARINHA DE BERINJELA (FB) E DAS FARINHAS MISTAS DE TRIGO E BERINJELA

Determinou-se o teor de umidade das farinhas conforme o método 6.1.1 do INSTITUTO ADOLFO LUTZ (1985) e o de cinzas e lipídios segundo a AOAC (1995).

O nitrogênio foi determinado pelo procedimento de Kjeldahl (AOAC, 1995), utilizando-se os fatores 6,25 (farinhas de berinjela e mistas) e 5,70 (farinha de trigo pura) para se obter o teor de proteína.

Os teores de fibra alimentar solúvel e insolúvel da farinha de berinjela foram determinados pelo método enzimático-gravimétrico (método 985.29, item 45.04.07) da AOAC (1990). Não foi necessária extração prévia de gordura. A fibra alimentar total foi estimada pela soma dos teores de fibra alimentar insolúvel e solúvel, descontando-se seus teores de proteína e cinza. Nas amostras de farinha de trigo e de farinhas mistas de trigo e berinjela foi determinada somente a quantidade de fibra alimentar total, não sendo separadas as frações solúvel e insolúvel. 
A quantidade de açúcares totais foi determinada conforme o método 4.13.3 do INSTITUTO ADOLFO LUTZ (1985) e os outros carboidratos por diferença.

\subsection{CARACTERIZAÇÃO FÍSICA DA FARINHA DE TRIGO (FT), DA FARINHA DE BERINJELA (FB) E DAS FARINHAS MISTAS DE TRIGO E BERINJELA}

Determinou-se o índice de absorção de água (IAA) pela metodologia de ANDERSON, CONWAY e PPFEIFER (1969), sendo calculado pela relação:

$I A A=$ Peso do resíduo centrifugado $(\mathrm{g})$ = g de gel/g de matéria seca

(Peso da amostra b.s.) - (Peso do resíduo evaporado) (g)

Para determinar o tamanho das partículas (classificação granulométrica) utilizou-se agitador de peneiras, modelo RO-TAP. Foram peneiradas $100 \mathrm{~g}$ de cada produto durante 10 minutos em conjunto de peneiras com 60, 80, 100, 120, 140, 170, 200 "mesh Tyler" (abertura de 0,25, 0,18,0,149,0,125,0,106, 0,090 e 0,074 mm, respectivamente) e a base. Em seguida, as quantidades retidas em cada peneira e na base foram pesadas e expressas em porcentagens, conforme GERMANI, BENASSI e CARVALHO (1997).

\subsection{ANÁLISE ESTATÍSTICA}

Utilizou-se delineamento experimental inteiramente casualizado (DIC). As análises da composição centesimal das farinhas foram constituídas por quatro tratamentos $(0,10,15$ e $20 \%$ de farinha de berinjela) e três repetições, perfazendo doze parcelas experimentais. Efetuou-se análise de regressão para a variável \% de farinha de berinjela (variável quantitativa), sendo a média (IAA) comparada pelo teste de Tukey ao nível de $5 \%$ de probabilidade.

As análises estatísticas foram realizadas utilizando-se o "software" SISVAR 4.03 (FERREIRA, 2000). 


\section{RESULTADOS E DISCUSSÃO}

Os resultados da composição centesimal da farinha de trigo (FT), da farinha de berinjela (FB) e das farinhas mistas de trigo e berinjela em diferentes concentrações, encontram-se na Tabela 1.

\section{TABELA 1 - COMPOSIÇÃO CENTESIMAL APROXIMADA DA FARINHA DE TRIGO, DA FARINHA DE BERINJELA E DAS FARINHAS MISTAS DE TRIGO E BERINJELA EM DIFERENTES CONCENTRAÇÕES}

\begin{tabular}{|c|c|c|c|c|c|c|c|c|c|}
\hline & & & & & Composi & (\% base se & & & \\
\hline & $\begin{array}{l}\text { Umidade } \\
(\mathrm{g} / 100 \mathrm{~g})\end{array}$ & Prote na & Cinzas & $\begin{array}{l}\text { Extrato } \\
\text { etđreo }\end{array}$ & $\begin{array}{l}\text { Fibra } \\
\text { alimentar } \\
\text { total }\end{array}$ & $\begin{array}{c}\text { Fibra } \\
\text { alimentar } \\
\text { sologel }\end{array}$ & $\begin{array}{c}\text { Fibra } \\
\text { alimentar } \\
\text { insologel }\end{array}$ & $\begin{array}{c}\text { A oeares } \\
\text { totais }\end{array}$ & $\begin{array}{l}\text { Carboi- } \\
\text { dratos }^{1}\end{array}$ \\
\hline $\begin{array}{l}\text { Farinha de } \\
\text { trigo (FT) }\end{array}$ & 13,41 & 13,40 & 0,67 & 1,47 & 3,46 & ND & ND & 3,00 & 78,00 \\
\hline $\begin{array}{l}\text { Farinha de } \\
\text { berinjela (FB) }\end{array}$ & 7,56 & 16,27 & 6,40 & 1,88 & 44,12 & 22,41 & 21,71 & 30,00 & 1,33 \\
\hline $\begin{array}{c}\text { F rmula I } \\
\text { (90FT:10FB) }\end{array}$ & 12,82 & 13,48 & 1,28 & 1,50 & 7,93 & ND & ND & 5,70 & 70,11 \\
\hline $\begin{array}{c}\text { F rmula II } \\
(85 F T: 15 F B)\end{array}$ & 12,32 & 13,51 & 1,66 & 1,53 & 9,97 & ND & ND & 7,05 & 66,28 \\
\hline $\begin{array}{l}\text { F rmula III } \\
(80 \mathrm{FT}: 20 \mathrm{FB})\end{array}$ & 12,32 & 13,65 & 1,85 & 1,55 & 12,24 & ND & ND & 8,40 & 62,31 \\
\hline
\end{tabular}

${ }^{1}$ Calculado por diferença (100 - proteína + cinzas + extrato etéreo + fibra alimentar total + açúcares totais).

ND - não determinado.

Pode-se observar que a FB apresentou teores de proteína, cinzas, fibra alimentar total e açúcares totais superiores aos da FT, enquanto o teor de carboidrato mostrou-se bastante inferior. Apesar do conteúdo de extrato etéreo da FB ser maior que o da FT, ambas são pobres em lipídios. A FB destacou-se pelo elevado teor de fibra alimentar total $(44,12 \%)$, sendo pouco mais da metade representado pela fibra alimentar solúvel. As diferentes concentrações de FB aumentaram o teor de proteína das farinhas mistas de trigo e berinjela (fórmulas I, II e III). Verificou-se também acréscimo significativo no conteúdo de cinzas com aumento da proporção de FB na mistura em decorrência do seu maior conteúdo de minerais.

A adição de FB promoveu alteração significativa no teor de fibra alimentar total das farinhas mistas, ocorrendo acréscimo gradativo conforme se 
aumentou o teor de farinha de berinjela. $O$ alto teor de fibra alimentar dessas farinhas permite apontá-las como alternativa para serem utilizadas em vários produtos, como os de panificação (biscoitos, pães e massas alimentícias), que são amplamente consumidos pela população.

O teor de açúcares totais na FB mostrou-se bastante elevado (30,0\% b.s.), podendo gerar economia ou até eliminar a adição de açúcar em produtos fermentados de panificação. Quanto à caracterização física, verificou-se que o IAA aumentou com o incremento na concentração de FB (Tabela 2).

\section{TABELA 2 - ÍNDICE DE ABSORÇÃO DE ÁGUA (IAA) DA FARINHA DE BERINJELA E DAS FARINHAS MISTAS DE TRIGO E BERINJELA}

IA A

(g de gel/g de matØria seca)

\begin{tabular}{lc}
\hline Farinha de berinjela (FB) & $11,63 \mathrm{a}$ \\
F rmula I (90FT:10FB) & $2,95 \mathrm{c}$ \\
F rmula II (85FT:15FB) & $3,19 \mathrm{bc}$ \\
F rmula III (80FT:20FB) & $3,31 \mathrm{~b}$
\end{tabular}

*Médias seguidas por letras iguais não diferem estatisticamente entre si pelo teste de Tukey a $5 \%$ de probabilidade.

É provável que o aumento do IAA, verificado com o incremento da proporção de farinha de berinjela na formulação da farinha mista, tenha ocorrido em virtude da maior quantidade de fibras com grande capacidade de absorver água existente na FB (fato pouco expressivo na FT). Tal aumento também é benéfico para formulações de produtos de panificação, pois permite maior incorporação de água à massa e aumenta o rendimento dos produtos finais.

A característica granulométrica do material farináceo constitui aspecto importante na elaboração de produtos de panificação (biscoitos, pães e massas alimentícias), visto que adequada distribuição percentual das partículas permite maior uniformidade no produto elaborado (VITTI, 1992). 
A granulometria da farinha de trigo é composta de $82,15 \%$ de partículas com tamanho menor que 100 mesh Tyler $(0,140 \mathrm{~mm}$ ) (Tabela 3). A FB mostrou-se bastante fácil de ser triturada, alcançando $77,1 \%$ das partículas com tamanho menor que 100 mesh Tyler. Tal fato evidencia a facilidade de se obter farinhas de berinjela com granulometria compatível com a da farinha de trigo.

\section{TABELA 3 - DISTRIBUIÇÃO PERCENTUAL DO TAMANHO DE PARTÍCULAS DA FARINHA DE TRIGO (FT) E DA FARINHA DE BERINJELA (FB)}

\begin{tabular}{cccc}
\hline mesh Tyler & $\begin{array}{c}\text { Abertura } \\
(\mathrm{mm})\end{array}$ & $\begin{array}{c}\text { FT } \\
(\%)\end{array}$ & $\begin{array}{c}\text { FB } \\
(\%)\end{array}$ \\
\hline 60 & 0,25 & 0,75 & 12,30 \\
80 & 0,18 & 17,10 & 10,60 \\
100 & 0,149 & 3,80 & 2,40 \\
120 & 0,125 & 12,50 & 6,80 \\
140 & 0,106 & 20,40 & 24,60 \\
170 & 0,090 & 5,95 & 16,20 \\
200 & 0,074 & 16,70 & 19,30 \\
base $>200$ & $<0,074$ & 22,80 & 7,80 \\
\hline
\end{tabular}

Verificou-se que a granulometria da farinha de berinjela é compatível com a da farinha de trigo, havendo distribuição relativamente homogênea das partículas entre as farinhas. Para MOHAMED (1990), a irregularidade no tamanho das partículas influencia negativamente as características físicas do produto final.

\section{CONCLUSÃO}

A farinha de berinjela apresentou elevado teor de fibra alimentar total, com ligeira predominância de fibras solúveis. Também apresentou alta quantidade de proteína bruta, cinzas e açúcares totais.

O aumento da concentração de farinha de berinjela nas misturas com farinha de trigo provocou incremento significativo nos teores de proteína bruta, sais minerais e fibra alimentar total da farinha mista. 
Maior quantidade de farinha de berinjela na farinha mista ampliou a capacidade da mistura em absorver água, podendo aumentar o rendimento da massa em produtos de panificação.

A farinha de berinjela é facilmente obtida na granulometria da farinha de trigo, facilitando sua homogeneização.

O alto teor de fibra alimentar, a alta capacidade de absorção de água e a facilidade de moagem fazem com que a farinha de berinjela constitua boa alternativa para ser misturada à farinha de trigo. A farinha mista pode ser empregada na elaboração de produtos de panificação (biscoitos, pães e massas alimentícias), ampliando a oferta de produtos para a complementação do aporte diário de fibras na alimentação.

\section{Abstract \\ WHEAT AND EGGPLANT MIXED FLOUR: PHYSICAL AND CHEMICAL CHARACTERISTICS}

The aim of the present work was to study the physical and chemical characteristics of eggplant flour and its combination with wheat flour. The eggplant flour presented high total dietary fiber content and high protein, ashes and total sugars contents. Higher concentration of eggplant flour in mixtures with wheat flour significantly enhanced protein mineral salts and total dietary fiber content of the mixed flours. The high dietary fiber content of the eggplant flour allows to designate it as utilization alternative in mixture with wheat flour in the elaboration of bakery products (cookies, breads and pasta). Greater quantity of eggplant flour in the mixed flour enlarges the mixture capacity to absorb water, being able to enhance the mass yield in bakery products. The eggplant flour is easily obtained at particle size similar to wheat flour, facilitating its homogenization.

KEY-WORDS: EGGPLANT-PHYSICAL AND CHEMICAL CHARACTERIZATION; WHEAT FLOUR; EGGPLANT FLOUR; MIXED FLOUR.

\section{REFERÊNCIAS}

1 ANDERSON, R.A.; CONWAY, H.F.; PFEIFER, V.F.; GRIFFIN Jr., L. Gelatinization of corn grits by roll-and extrusion-cooking. Cereal Science Today, Saint Paul, v.14, n.1, p.4-11, 1969.

2 AOAC. Association of Official Analytical Chemists. Official methods of analysis of AOAC international. $16^{\text {th }}$ ed. Washington, 1995. $1141 \mathrm{p}$.

3 AOAC. Association of Official Analytical Chemists. Official methods of analysis of AOAC international. $15^{\text {th }}$ ed. Washington, 1990. p.1105-1106. 
ARTZ, W.E.; WARREN, C.C.; MOHRING, A.E.; VILLOTA, R. Incorporation of corn fiber into sugar snap cookies. Cereal Chemistry, v.67, n.3, p.303305, 1990.

EL-DASH, A.A.; GERMANI, R. Tecnologia de farinha mistas: uso de farinhas mistas na produção de biscoitos. Brasília: Empresa Brasileira de Pesquisa de Tecnologia Agroindustrial de Alimentos (EMBRAPA - SPI), 1994. v. 6.

EMBRAPA HORTALIÇAS. Pós-colheita da berinjela. Disponível em: $<$ www.embrapa.br:8080/aplic/fontes.nsf/00d804fe9441d8820325 65be00613fc2/e36c36eb6f718b0903256567006974fa?OpenDocument. Acesso em 24 de abril de 2001.

7 FERREIRA, D. F. Análises estatísticas por meio do Sisvar para Windows versão 4.03. In: REUNIÃO ANUAL DA REGIÃO BRASILEIRA DA SOCIEDADE INTERNATIONAL DE BIOMETRIA, 45, 2000, São Carlos. Resumos... São Carlos: Universidade Federal de São Carlos (UFSCar), 2000. p.255-258.

GERMANI, R.; BENASSI, V.T.; CARVALHO, J.L.V. Métodos de avaliação de grão e farinha de trigo. Rio de Janeiro: EMBRAPA-CTAA, 1997. 84 p. (EMBRAPA-CTAA, Documentos, n. 28).

GUIMARÃES, P.R.; GALVÃO, A.M.P.; BATISTA, C.M.; AZEVEDO, G.S.; OLIVEIRA, R.D.; LAMOUNIER, R.P.; FREIRE, N.; BARROS, A M.D.; SAKURAI, E.; OLIVEIRA, J.P.; VIEIRA, E.C.; LEITE-ALVAREZ, J.I. Eggplant (Solanum melongena) infusion has a modest and transitory effect on hypercholesterolemic subjects. Brazilian Journal of Medical and Biological Research, São Paulo, v.33, p.1027-1036, 2000.

HOSENEY, R.C. Principles of cereal science and technology. American Association of Cereal Chemists (AACC), Saint Paul, p.76-80, 1990.

INSTITUTO ADOLFO LUTZ. Normas analíticas do Instituto Adolfo Lutz: métodos químicos e físicos para análise de alimentos. 3.ed. São Paulo, 1985. v. 1.

JORGE, P.A.R.; NEYRA, L.C.; OSAKI, R.M.; ALMEIDA, E.; BRAGAGNOLO, N. Efeito da berinjela sobre os lípides plasmáticos, a peroxidação lipídica e a reversão da disfunção endotelial na hipercolesterolemia experimental. Arquivos Brasileiros de Cardiologia, São Paulo, v. 70, n. 2, p. 87-91, 1998.

13 MOHAMED, S. Factors affecting extrusion characteristics of expanded starch-based products. Journal of Food Processing Preservation, Westport, v.14, p.437-452, 1990.

14 SILVA, M.R. Caracterização química e nutricional da farinha de jatobá (Hymenaea stigonocarpa Mart.): desenvolvimento e otimização de produtos através de testes sensoriais afetivos. Campinas, 1997. $154 \mathrm{f}$. Tese (Doutorado em Ciência da Nutrição) - Faculdade de Engenharia de Alimentos, Universidade Estadual de Campinas (UNICAMP).

15 VITTI, P. Avaliação tecnológica dos produtos elaborados com farinha de trigo (pão, macarrão, biscoito). Campinas: Instituto de Tecnologia de Alimentos (ITAL), Centro de Tecnologia de Farinhas e Panificação, 1992. p.14-21. 